\title{
Morel-Lavallee sendromu: cilt nekrozu ile seyreden Morel Lavallee lezyonu
}

\author{
Morel-Lavallee syndrome: morel-Lavallee lesion with skin necrosis
}

Özgen Kıvanç, Erkan Kural, Barış Altaylı, İnci Gökalan Kara

Gönderilme tarihi:17.06.2020

Kabul tarihi:19.04.2021

Öz

Morel-Lavallee Sendromu (MLS), subkutan dokunun altta yatan fasyadan künt bir travmayla ayrıldığı (kapalı degloving), oldukça nadir görülen yumuşak bir doku travmasıdır. Nadir görülen bir durumdur ve genellikle büyük trokanter, kanat, kalça ve lumbodorsal bölgelerde görülür. Erken tanı durumunda konservatif tedavi yöntemleri yoluyla iyileşme sağlanırken, tanı koymada gecikme durumunda, efüzyon enfekte olmakta, geniş bir cilt nekrozuna yol açarak morbiditeyi artırmaktadır. Bu çalışmada, sağ uyluk lateral, trokanterik, ve lumbosakral bölgelerde geniş ve cilt nekrozu ile seyreden MLS Lezyonu olgusu ortaya konulmaktadır.

Anahtar kelimeler: Morel-Lavallee sendromu, künt travma, kapalı yaralanma.

Kıvanç Ö, Kural E, Altaylı B, Gökalan Kara İ. Morel-Lavallee sendromu: cilt nekrozu ile seyreden Morel Lavallee lezyonu. Pam Tıp Derg 2021;14:760-763.

\begin{abstract}
Morel-Lavallee Syndrome (MLS) is a rare soft tissue trauma in which the subcutaneous tissue is separated from the underlying fascia (closed degloving) due to a blunt trauma. It is a rare condition and usually seen in large trochanter, flank, hip and lumbodorsal regions. Early diagnosis achieves the treatment by conservative methods, if the diagnosis delayed, the effusion becomes infected and increases the morbidity by causing wide skin necrosis. In this article, we present a case of Morel-Lavallee lesion in the right thigh lateral, trochanteric, and lumbosacral region with a wide and skin necrosis.
\end{abstract}

Key words: Morel-Lavallee sendromu, blunt trauma, closed injury.

Kıvanc O, Kural E, Altayli B, Gokalan Kara I. Morel-Lavallee syndrome: Morel-Lavallee lesion with skin necrosis. Pam Med J 2021;14:760-763.

\section{Giriş}

MLS, deri ve deri altı dokunun altta yatan fasyadan künt bir travma ile ayrılarak, kapalı eldiven parmağı şeklinde (degloving) soyulan bölgenin hematom ve sıvılaşmış yağ dolu bir boşlukla seyreden yumuşak doku yaralanmasıdır. Bu durum ilk olarak 1853 yılında Fransız Doktor Maurice Morel-Lavallée tarafından tanımlanmıştır. MLS tanısı için netleşmiş kriterler bulunmamaktadır ancak literatürde travma bölgesinde hislerde azalma, yumuşaklık, morarma ve şişlik (hematom formasyonu) alanı MLS tanısı için öne çıkmaktadır [1]. Manyetik rezonans görüntüleme (MRG), MLS'nin araştırılması için tercih edilen bir yöntem şeklidir. Enfeksiyon veya yoğun cilt nekrozu gibi komplikasyonların önlenmesinde lezyonun erken teşhisi ve tedavisi önemlidir.

\section{Olgu sunumu}

Çalıştığı fabrikada makineye kapılarak yaralanan kırk dört yaşlarında, erkek hasta sol kalça ve sağ bacak ağrısı ile Pamukkale Üniversitesi Tıp Fakültesi Hastanesi Acil Servisi'ne başvurmuştur. Hastanın rutin tetkikleri ve görüntülemeleri yapılmıştır. Yapılan genel muayenede hastanın bilincinin açık ve oryente-koopere olduğu gözlenmiştir. Fiziksel muayene sonuçlarına göre, hastanın sağ diz altında $6 \times 4 \mathrm{~cm}$ ve sol ayak dorsalde $2 \times 1 \mathrm{~cm}$ boyutlarında kesiler vardır. Sağ ayak bileği hareketlerinin ağrılı ve kısıtlı olduğu, sol kalçada palpasyonla hassasiyet izlenmiştir. Acil serviste

Özgen Kıvanç, Dr. Öğr. Üye. Pamukkale Üniversitesi Tıp Fakültesi, Plastik Rekonstrüktif ve Estetik Cerrahisi Anabilim Dalı, Denizli, Türkiye, e-posta: drozgenkivanc@gmail.com (https://orcid.org/0000-0003-2515-6186) (Sorumlu Yazar)

Erkan Kural, Arş. Gör. Pamukkale Üniversitesi Tıp Fakültesi, Plastik Rekonstrüktif ve Estetik Cerrahisi Anabilim Dalı, Denizli, Türkiye, e-posta: ekural88@gmail.com (https://orcid.org/0000-0002-0376-6023)

Barış Altaylı, Arş. Gör. Pamukkale Üniversitesi Tıp Fakültesi, Plastik Rekonstrüktif ve Estetik Cerrahisi Anabilim Dalı, Denizli, Türkiye, e-posta: barisaltayli7@gmail.com (https://orcid.org/0000-0001-7080-8222)

İnci Gökalan Kara, Prof. Dr. Pamukkale Üniversitesi Tıp Fakültesi, Plastik Rekonstrüktif ve Estetik Cerrahisi Anabilim Dalı, Denizli, Türkiye, e-posta: incigk@yahoo.com (https://orcid.org/0000-0002-4701-638X) 
çekilen bilgisayarlı tomografide, hastanın sağ superior pubik ramusta hafif deplase fraktür, sağ fibula baş kesiminde deplase parçalı kırık hatları ile sol kalça eklemini oluşturan femur şaft proksimalinde intertrokanterik uzanımı olan kırık hatlar tespit edilmiştir. Ayrıca, sağ uyluk lateral ve posterolateralde $55 \times 29 \mathrm{~cm}$ boyutunda

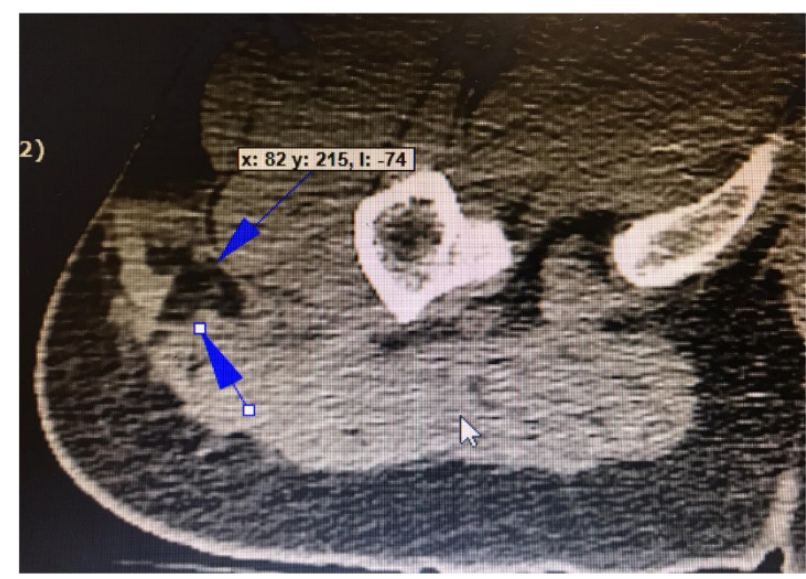

hematoma uyumlu olabilecek koleksiyon görülmüştür (Resim 1).

Hasta acil olarak ortopedi bölümü tarafından ameliyata alınarak, sol femur sağ tibia, fibula distal ve sağ ayak tarsal kemikte bulunan kırık hatların redüksiyonu ve fiksasyonu yapılmıştır.

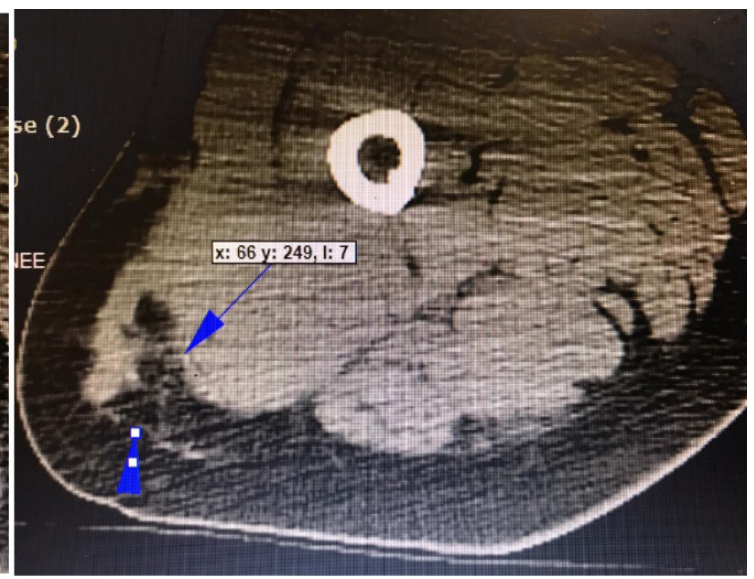

Resim 1. Hastanın travma günü çekilen tomografide hematom düşündüren kolleksiyon görülmektedir

Sekiz gün sonra yapılan ikinci operasyonda, sağ tibia ve fibula eksternal fiksatörler çıkarılarak, plak ve vida ile fiksasyon sağlanmıştır. Bu süreçte, hasta sağ uyluk, lumbal bölgeden popliteaya uzanan cilt altı yoğun sıvı kolleksiyonu ve cilt nekrozu karşısında acil servise 10 gün sonra plastik cerrahi bölümüne yönlendirilmiştir (Resim 2).

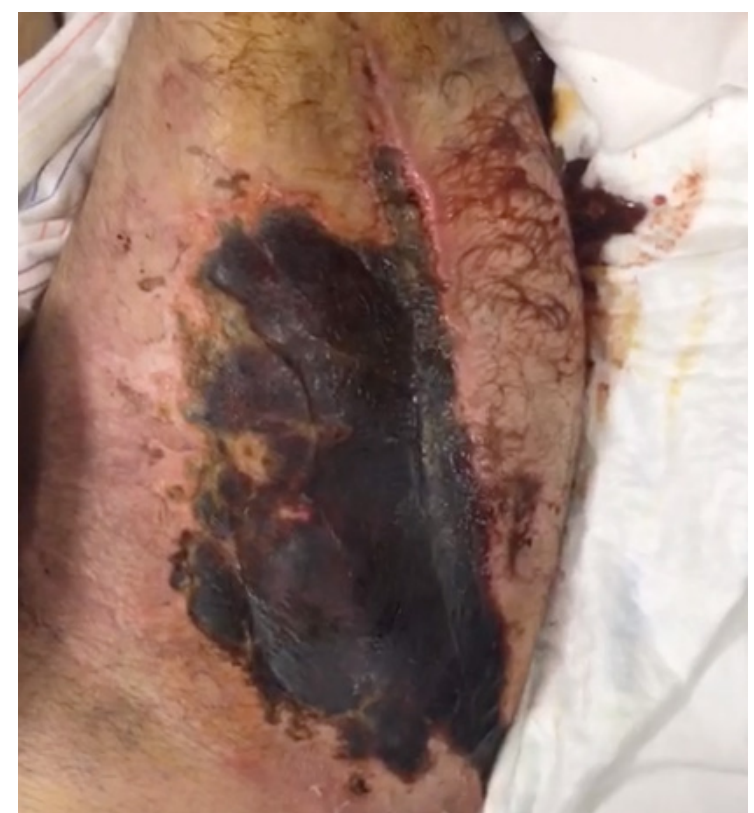

Resim 2. Sağ uyluk lateralinde $20 \times 15 \mathrm{~cm}$ cilt nekrozu ve altında yaygın sıvı kolleksiyonu (8. gün)
Hasta plastik cerrahi servisine yatırılarak, ameliyata alınmıştır. Operasyonda hastaya nekrotik doku debridmanı uygulanmıştır (Resim 3). Hastanın cilt altında yaygın doku nekrozu ve enfeksiyonu taşıdığı gözlenmiştir. Kültür örneği gönderilerek, gerekli antibiyotik tedavisine başlanmıştır. Tedavi süresince hastaya günlük olarak anestezi altında yara yeri debridmanı ve pansumanı yapılmıştır. Ameliyattan beş gün sonra yara yerinde enfeksiyonun gerilediği izlenmiştir. İyileşme hızını artırmak ve granülasyon oluşumunu artırmak için vakum yardımlı kapama seti ile pansuman yapılmıştır. Toplamda 2 gün, 3 seanslık, vakum yardımlı kapama terapisi ardından, yara bölgesinin kapanmaya hazır olduğu görülmüştür. Hasta ameliyata alınarak, yara primer olarak onarılarak, cilt altına 2 adet drenaj tüpü yerleştirilmiştir (Resim 4). Operasyonu izleyen üçüncü günde drenaj tüpleri çıkartılmıştır. Operasyonu izleyen beşinci günde yara bölgesinde hiçbir komplikasyona rastlanmadığı için, hasta uygun bir reçeteyle taburcu edilmiştir. 


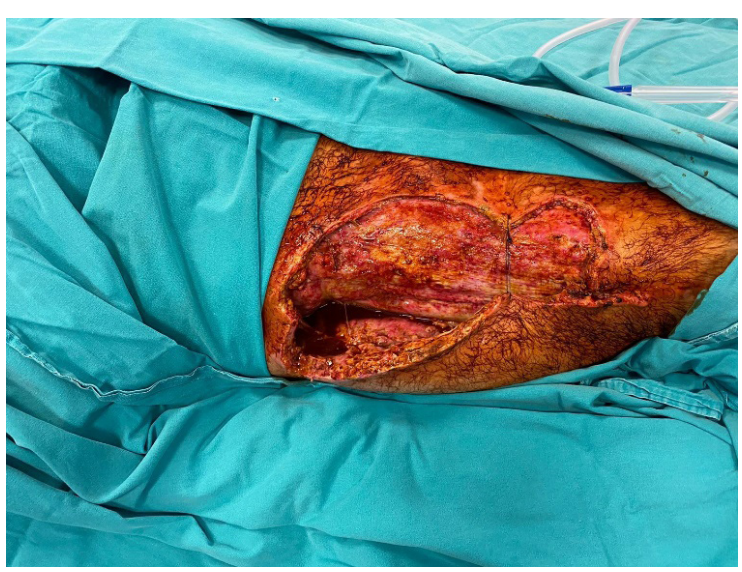

Resim 3. Debridman yapıldıktan sonra retansiyon suturleri atıldı (9. gün)

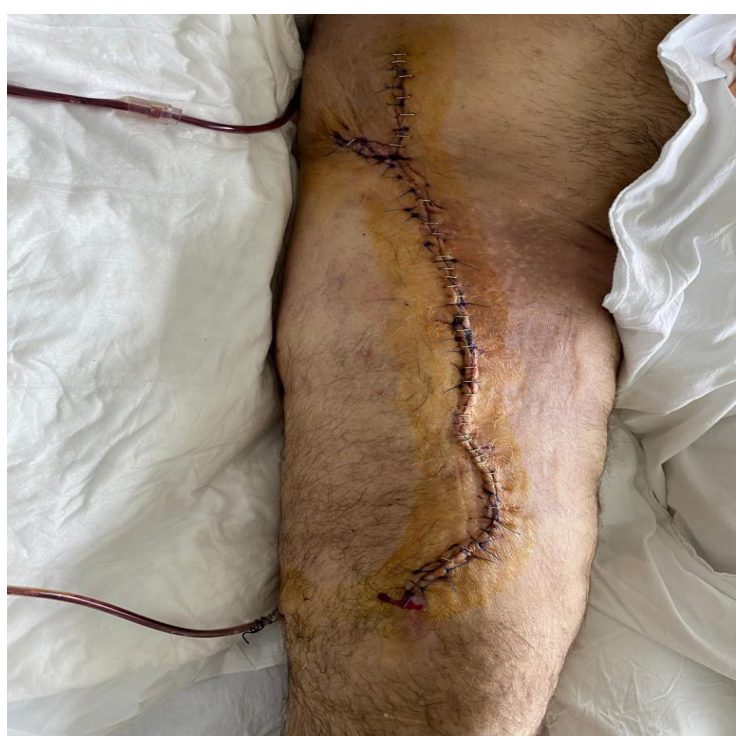

Resim 4. Yara yeri primer onarıldı (21.gün)

\section{Tartışma}

Morel-Lavallee Sendromu (MLS) tanıSI, ilk olarak 1863 yılında Victor Morel Lavallée tarafından konmuştur [2]. Diğer yandan, MLS, Morel-Lavallee Lezyonu, Morel-Lavallee Seroması, travma sonrası yumuşak doku kisti, travma sonrası ekstravazasyonu veya MorelLavallee Efüzyonu olarak da adlandırımaktadır [3]. MLS'nin en yaygın görüldüğü bölge trokanterdedir. İkinci sıklıkta görülen bölge pelvis veya uyluk çevresidir [4]. Buna ek olarak, gluteal, lumbosakral bölgeler ile alt bacak daha az görülen bölgelerdir [5].

Morel-Lavallee lezyonları (MLL), cilt yüzeyinde etki eden travmatik makaslama veya ezilme tarzı yaralanma nedeniyle cildin ve subkutan dokunun altta yatan fasyadan ayrılması sonucu oluşur [6]. Genellikle, perifasyal plan, bozulan kılcal damarlar nedeniyle kan, lenf ve debrisle dolar. Lezyonun yavaş ve sürekli büyüme seyrine bağlı olarak, enflamatuar reaksiyon, periferik bir kapsül oluşumuyla sonuçlanır [4]. Akut bir travmada MRS enfeksiyonu önlemek için cerrahi müdahale şarttır [2]. Bununla birlikte, klinik tanıyı zorlaştıran, efüzyonların başlangıçta gözden kaçırılması ya da zamanla ortaya çıkması söz konusudur [7].

MLS genellikle birkaç saat içinde ya da aylar hatta yıllar sonra görülebilmektedir. Genellikle sorunun kaynağı altta yatan kırıklardır, ancak kırık dışında farklı nedenlerle benzer tabloya rastlanmaktadır. Bu lezyonlar çoğunlukla tek tarafıdır. Hastalar genellikle ağrı, şişlik ve sertlik şikayetinden yakınır. Klinik muayenede, hastada cilt altında dalgalanma hissedilebilen kontur deformitesi gözlenmektedir. Ciltte renk değişikliği şart değildir. Genellikle his kaybı mevcuttur ve cilt nekrozu gelişmektedir [8].

Günümüzde MLS tedavisinde etkin bir tedavi şeması olmamakla birlikte, etkinlik gösteren yöntemler, konservatif yaklaşım, perkütan aspirasyon, sklerodesis ve açık cerrahi tedavi den oluşan yöntemlere yer veren geniş bir literatür bulunmaktadır [9].

Sonuç olarak MLS, travma sonrası kılcal damarların bozulması nedeniyle hemolenf ve nekrotik yağ içeren efüzyonla seyreden, bir kapalı degloving yaralanma türüdür. Erken dönemde MLS semptompları gösteren hastalara, ileri görüntüleme tetkikleriyle tanı koyma, aspirasyon, dren uygulaması ve baskılı pansuman yapılmalıdır. MLS tanının atlandığı durumlarda, sürece seroma enfeksyonu, kapsül oluşumu ve cilt nekrozu eşlik ettiği gözlenmektedir.

Çıkar ilişkisi: Yazarlar çıkar ilişkisi olmadığını beyan eder.

\section{Kaynaklar}

1. Muneer M, El Menyar A, Abdelrahman H, et al. Clinical presentation and management of pelvic MorelLavallee injury in obese patients. J Emerg Trauma Shock 2019;12:40-47. https://doi.org/10.4103/JETS. JETS_37_18

2. Mellado JM, Bencardino JT. Morel-Lavallée lesion: review with emphasis on MR imaging. Magnetic resonance imaging Clin N Am 2005;13:775-782. 
3. Mellado JM, Pérez del Palomar L, Díaz L, Ramos A, Saurí A. Long-standing Morel-Lavallée lesions of the trochanteric region and proximal thigh: MRI features in five patients. AJR. American journal of roentgenology 2004;182:1289-1294. https://doi.org/10.2214/ ajr.182.5.1821289

4. HakDJ, OlsonSA, MattaJM. Diagnosisandmanagement of closed internal degloving injuries associated with pelvic and acetabular fractures: the Morel-Lavallée lesion. The Journal of Trauma 1997;42:1046-1051. https://doi.org/10.1097/00005373-199706000-00010

5. Moran DE, Napier NA, Kavanagh EC. Lumbar MorelLavallée effusion. Spine J 2012;12:1165-1166. https:// doi.org/10.1016/j.spinee.2012.11.019

6. Weiss NA, Johnson JJ, Anderson SB. Morel-Lavallee lesion initially diagnosed as quadriceps contusion: ultrasound, MRI, and importance of early intervention. West J Emerg Med 2015;16:438-441. https://doi. org/10.5811/westjem.2015.3.25148

7. Parra JA, Fernandez MA, Encinas B, Rico M. MorelLavallée effusions in the thigh. Skeletal Radiol 1997;26:239-241.

8. Gummalla KM, George M, Dutta R. Morel-Lavallee lesion: case report of a rare extensive degloving soft tissue injury. Ulus Travma Acil Cerrahi Derg 2014;20:6365. https://doi.org/10.5505/tjtes.2014.88403

9. Singh R, Rymer B, Youssef B, Lim J. The MorelLavallée lesion and its management: a review of the literature. J Orthop 2018;15:917-921. https://doi. org/10.1016/j.jor.2018.08.032

Hasta onamı: Hastadan yazılı hasta onamı alınmıştır.

\section{Yazarların makaleye katkıları}

Morel-Lavallee sendromu: cilt nekrozu ile seyreden Morel-Lavallee Lezyonu başlıklı olgu sunumuzda, hastanın operasyonları Ö.K., E.K. ve B.A. tarafından yapılmıştır. Literatür taraması ve yazının yazılması Ö.K., E.K. ve B.A. tarafından yapılmış, Makalenin bilimsel yönünün incelenmesi, gerekli olan bilgilerin eklenmesi ve değerlendirilmesi bahriye İ.G.K. tarafından yapılmıştır. 


\title{
Göçmen bir hastada nutrisyonel rikets ve nadir klinik yansıması: myelofibrozis
}

\author{
Nutritional rickets in a refuge patient and its rare clinical reflection: myelofibrosis
}

Doğan Köse, Seher Aydın

Gönderilme tarihi:13.10.2020

Kabul tarihi:23.11.2020

\section{Öz}

Rikets; epifizyal büyüme plağının yetersiz mineralizasyonu sonucu oluşan ve nadiren miyelofibrozise sebep olabilen bir hastalıktır. Sekiz aylık mülteci bir kız hasta, ateş ve solukluk şikâyeti ile başvurdu. Hastanın; bilateral krepitan ralleri vardı, karaciğeri $2-3 \mathrm{~cm}$, dalağı $7 \mathrm{~cm}$ palpe ediliyordu. El bileği kemikleri geniş, kraniotabes ve raşitik rozaryleri mevcuttu. Lökosit sayısı: $36,000 / \mathrm{mm}^{3}$, hemoglobin: $6 \mathrm{~g} / \mathrm{dl}$ ve trombosit sayısı: 50,000/ $\mathrm{mm}^{3}$ idi. Periferik yaymasında; yaygın normoblastlar ve myeloid seri öncülleri görüldü. Kalsiyumu: 8,8 mg/dl, fosforu: $1,0 \mathrm{mg} / \mathrm{dl}$, alkalen fozfatazı: $4099 \mathrm{U} / \mathrm{L}$, D vitamini düzeyi: $5,12 \mathrm{ng} / \mathrm{ml}$ ve paratiroid hormonu: $1364 \mathrm{pg} / \mathrm{mL}$ idi. Akciğer grafisinde; bilateral parakardiyak infiltrasyonları ve el bilek grafisinde; kadehleşme görüntüsü mevcuttu. Kemik iliği değerlendirmesi; bazı normoblast çekirdeklerinde görülen anormal lobülasyonlar dışında normaldi. Aile onam vermediği için kemik iliği biyopsisi yapılamadı. 4000 IU/gün oral D vitamini ile yaklaşık bir ay sonra hastanın tüm hemogram değerleri ve periferik yayması tamamen düzeldi. Son kalsiyumu: 9,6 mg/dl, fosforu: 4,6 mg/dl, alkalen fozfatazı: $487 \mathrm{U} / \mathrm{L}, 25$-hidroksi vitamin D düzeyi: $8,8 \mathrm{ng} / \mathrm{ml}$ ve parathormonu: $122 \mathrm{pg} / \mathrm{mL}$ idi. Son yıllarda yoğun göç alan ülkemizde rikets vakalarında artış muhtemeldir. Bu vakaların myelofibrozis gibi nadir, hayatı tehdit edebilen ve tedavi ile tamamen geri dönebilen klinik yansımaları ile karşımıza çıkabileceği unutulmamalıdır.

Anahtar kelimeler: Çocuk, myelofibrozis, rikets.

Kose D, Aydın S. Göçmen bir hastada nutrisyonel rikets ve nadir klinik yansıması: myelofibrozis. Pam Tıp Derg 2021;14:764-767.

\begin{abstract}
Rikets; it is a disease that occurs as a result of insufficient mineralization of the epiphyseal growth plate and can rarely cause myelofibrosis. An eight-month-old refugee girl presented with fever and paleness. She had bilateral crepitant rales, her liver was $2-3 \mathrm{~cm}$ and her spleen was $7 \mathrm{~cm}$ palpable. Craniotabes, widening of the wrists and rachitic rosaries were prominent. White blood cell was $36.000 / \mathrm{mm}^{3}$, hemoglobin was $6 \mathrm{~g} / \mathrm{dl}$ and thrombocyte was $50.000 / \mathrm{mm}^{3}$. In peripheral smear; numerous normoblasts and myeloid series precursors were seen. Calcium: $8.8 \mathrm{mg} / \mathrm{dl}$, phosphorus: $1.0 \mathrm{mg} / \mathrm{dl}$, alkaline phosphatase: $4099 \mathrm{U} / \mathrm{L}$, vitamin D level: $5.12 \mathrm{ng} / \mathrm{ml}$ and parathyroid hormone: $1364 \mathrm{pg} / \mathrm{mL}$. In chest radiography; bilateral paracardiac infiltrations was noted and wrist radiography showed cupping and fraying of the distal Radius and ulna. Bone marrow assessment; it was normal except for abnormal lobulations seen in some normoblast nuclei. Bone marrow biopsy could not be performed because the family did not give consent. Approximately one month later, with $4000 \mathrm{lU} /$ day oral vitamin D, all hemogram values and peripheral smear of the patient completely recovered. Final calcium: $9.6 \mathrm{mg} / \mathrm{dl}$, phosphorus: $4.6 \mathrm{mg} /$ dl, alkaline phosphatase: $487 \mathrm{U} / \mathrm{L}, 25$-hydroxy vitamin D level: $8.8 \mathrm{ng} / \mathrm{ml}$, and parathyroid hormone: $122 \mathrm{pg} / \mathrm{mL}$. An increase in rickets cases is likely in our country, which has received intense immigration in recent years. It should be kept in mind that these cases may present with rare, life-threatening clinical manifestations such as myelofibrosis, which can be completely reversed with treatment.
\end{abstract}

Key words: Child, myelofibrosis, rickets.

Köse D, Aydın S. Nutritional rickets in a refuge patient and its rare clinical reflection: myelofibrosis. Pam Med J 2021;14:764-767.

Doğan Köse, Doç. Dr. Harran Üniversitesi Tıp Fakültesi, Çocuk Sağlığı ve Hastalıkları Anabilim Dalı, Çocuk Hematoloji ve Onkoloji Bilim Dalı, Şanlıurfa, Türkiye, e-posta: drdogankose@gmail.com (https://orcid.org/0000-0002-2903-2976) (Sorumlu Yazar)

Seher Aydın, Arş. Gör. Harran Üniversitesi Tıp Fakültesi, Çocuk Sağlı̆̆ı ve Hastalıkları Anabilim Dalı, Şanlıurfa, Türkiye, e-posta: seherselin@hotmail. com (https://orcid.org/0000-0003-2421-0128) 


\section{Giriş}

Rikets; epifiz plakları kapanmadan önce gelişen, defektif kondrosit farklılaşması ve büyüme plağının ve osteoid dokunun yetersiz mineralizasyonu ile karakterize bir hastalıktır [1]. D vitamini, kalsiyum ve fosforun yetersiz alımları, metabolik hastalıklar, malabsorbsiyon, kronik hastalıklar, intoksikasyonlar ve ilaç kullanımları riketse yol açabilir [2]. Ülkemizde nutrisyonel rikets neredeyse tamamen $D$ vitamini eksikliğine bağlıdır [3]. D vitamininin en önemli fonksiyonu; bağırsaktan kalsiyum ve fosfor emilimini sağlayarak, en uygun kemik mineralizasyonunu sağlamaktır [4].

Riketsin çok nadir bir etkisi de miyelofibrozise sebep olmasıdır [5]. Birincil (idiyopatik) miyelofibrozis, çocuklarda çok nadir görülür. Sekonder formu ise; akut lösemi, non-hodgkin lenfoma, langerhans hücreli histiyositoz, fanconi anemisi, tüberküloz, leşmanya, sistemik lupus eritematozus, juvenil romatoid artrit ve rikets gibi hastalıklara eşlik edebilir [6].

Biz bu yazıda riketsin nadir bir klinik yansıması olarak myelofibrozis gelişen mülteci bir hastayı literatür bilgisi ile paylaşmayı amaçladık.

\section{Olgu sunumu}

Sekiz aylık mülteci bir kız hasta, ateş, solukluk ve ciltte morarma şikâyeti ile kliniğimize getirildi. Öyküsünden; ateş ile beraber zaman zaman öksürük şikayetinin olduğu ve verilen antibiyotik tedavilerine geçici cevaplar alındığı öğrenildi. Soy geçmişinde bir özelliği olmayan hastanın özgeçmişinde de yenidoğan döneminde geçirdiği hiperbilirubinemi dışında bir özellik yoktu.

Fizik muayenesinde; genel durumu orta ve cildi soluktu. Ön fontaneli bombe ve pulsatildi. Akciğerlerde bilateral krepitan ralleri mevcuttu. Karaciğeri 2-3 cm ve dalağı yaklaşık $7 \mathrm{~cm}$ ele geliyordu. El bileği kemikleri geniş, kraniotabes ve raşitik rozaryleri mevcuttu. Diğer sistem muayeneleri doğaldı.

Yapılan tetkiklerinden; lökosit sayısı: $36000 /$ $\mathrm{mm}^{3}$, nötrofil: $13000 / \mathrm{mm}^{3}$, hemoglobin: $6 \mathrm{~g} / \mathrm{dl}$, MCV: $87 \mathrm{fL}$ ve trombosit sayısı: $50000 / \mathrm{mm}^{3}$ idi. Periferik yaymasında; blast görülmedi ancak yaygın normoblastlar ve yaygın myeloid seri öncülleri dikkati çekiyordu. Direk Coombs: (-), retikülosit: \%11,8 idi. Kalsiyum: $8,8 \mathrm{mg} / \mathrm{dl}$, fosfor: $1,0 \mathrm{mg} / \mathrm{dl}, \mathrm{LDH}: 3223 \mathrm{U} / \mathrm{L}$ ve alkalen fozfataz: $4099 \mathrm{U} / \mathrm{L}$ olan hastanın diğer biyokimyasal tetkikleri ve tam idrar tahlili normaldi. PT: 14 , aPTT: 24, TORCH ve EBV (-) idi. 25-hidroksi vitamin $D$ düzeyi: $5,12 \mathrm{ng} / \mathrm{ml}$, paratiroid hormon: $1364 \mathrm{pg} / \mathrm{mL}$, B12: $309 \mathrm{pg} / \mathrm{mL}$, folik asit: $12,5 \mathrm{ng} /$ $\mathrm{ml}$, ferritin: 29,9 ng/ml, C3: 84,7 mg/dL, C4: 23,8 $\mathrm{mg} / \mathrm{dL}, \operatorname{lgG}: 907 \mathrm{mg} / \mathrm{dL}$, IgA: $105 \mathrm{mg} / \mathrm{dL}$, IgM: $107 \mathrm{mg} / \mathrm{dL}$, IgD: bakılamadı ve $\operatorname{lgE}:<5 \mathrm{IU} / \mathrm{mL}$ idi.

Arka ön akciğer grafisinde; bilateral parakardiyak infiltrasyonları (Resim 1) ve el bilek grafisinde ise; kadehleşme görüntüsü mevcuttu (Resim 2). Batın ultrasonografisinde; karaciğeri yaklaşık $99 \mathrm{~mm}$ (N: 68,7-75,4 mm), dalağı yaklaşık 95 mm (N: 59,6-66,5) olarak ölçüldü. Diğer yapıları normaldi. Ayırıcı tanı amacıyla yapılan kemik iliği değerlendirmesi şöyleydi: Normoselüler kemik iliği, tüm serilerden yeteri kadar hücre görüldü. $\% 2$ blast sayıldı. Bazı normoblast çekirdeklerinde anormal lobülasyonlar dikkati çekiyordu. Leishmania, depo hücresi ve hemofagosit görülmedi. Megakaryositler sayıca normaldi.

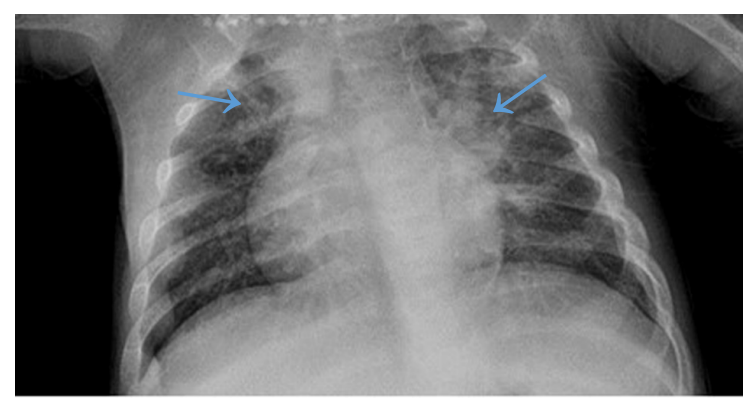

Resim 1. Ön arka akciğer grafisinde bilateral infiltrasyon

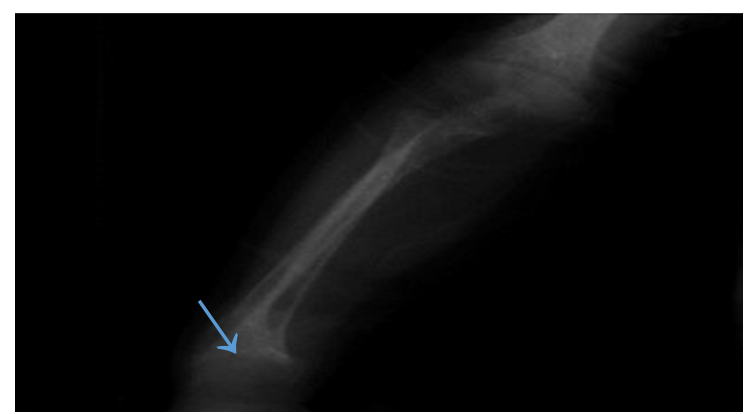

Resim 2. El bilek grafisinde kadehleşme görüntüsü 